\title{
Context-Sensitive Implementation of Clinical Pharmacy Missions Within an Academic Hospital
}

\author{
Romaric MARCILLY ${ }^{\mathrm{a}, \mathrm{b}, 1}$, Jeremie COLLIAUX ${ }^{\mathrm{b}}$, Chloé ROUSSELIERE $^{\mathrm{c}}$, Bertrand \\ DECAUDIN $^{\text {c, d }}$, Jean-Baptiste BEUSCART ${ }^{\text {a, e }}$, and Sylvia PELAYO ${ }^{\text {a }, \mathrm{b}}$ \\ ${ }^{a}$ Univ. Lille, CHU Lille, ULR 2694 - METRICS : Évaluation des technologies de santé \\ et des pratiques médicales, F-59000 Lille, France \\ ${ }^{b}$ Inserm, CIC-IT 1403, F-59000 Lille, France \\ ${ }^{c}$ CHU Lille, Institut de pharmacie, F-59000 Lille, France \\ ${ }^{d}$ Univ. Lille, CHU Lille, ULR 7365 - GRITA - Groupe de Recherche sur les formes \\ Injectables et les Technologies Associées, F-59000 Lille, France \\ ${ }^{e}$ CHU Lille, Service de gériatrie, F-59000 Lille, France
}

\begin{abstract}
Clinical pharmacy activities contribute to improve patient safety. Yet, the work system's characteristics influence how clinical pharmacy activities are performed and conversely clinical pharmacy causes that work system to evolve. This exploratory study aims to identify the different ways in which clinical pharmacy activities are performed in different units of a large academic hospital. Interviews and observations have been performed to identify in each ward the clinical pharmacy activities implemented and how they are carried out.
\end{abstract}

Keywords. Clinical pharmacy, ethnographic method, context, pharmaceutical analysis, pharmaceutical intervention

\section{Introduction}

Clinical pharmacy "is a health science discipline in which pharmacists provide patient care that optimizes medication therapy and promotes health, and disease prevention" (American college of clinical pharmacy [1]). Several studies have shown that clinical pharmacy contribute to reducing the cost of care [2], but also the number of medication errors [3], the number of adverse drug reactions [4] and finally the length of hospital stay and the mortality rate [5]. Implementing a new practice, such as clinical pharmacy, in a highly complex work system needs the anticipation of the profound impact on work processes, or possible conflicts with existing organizations, facilities, and beliefs. The new work practice causes that work system to evolve; conversely, the characteristics of the work system will influence how the new work practice is performed. In the field of clinical pharmacy, several factors are known to facilitate, affect, or hinder the setup of clinical pharmacy: political factors (e.g., legislative framework, political drive, financial support from the government and/or hospital administration) [6-7], factors related to human resources (e.g., workload/available human resources ratio, definition of tasks) [6-

\footnotetext{
${ }^{1}$ Corresponding Author: Romaric Marcilly: romaric.marcilly@univ-lille.fr
} 
8], factors related to the training and recognition of clinical pharmacists (e.g., existence of specialized academic programs, recognition of degree and position, salary) [6-9], factors related to communication (e.g., between pharmacists, between pharmacists and physicians, or with institutions about the benefits of clinical pharmacy) [6-9], and factors related to the work organization (e.g., presence of the pharmacist in or outside the clinical department, access to patient information) $[6,8,10]$. This exploratory study aims to identify the different ways in which clinical pharmacy is performed in a large university hospital along with contextual factors that may influence how it is performed.

\section{Study context}

Clinical pharmacy is particularly well established in Anglo-Saxon countries, where the pharmacist is an integral part of clinical services and whose role is valued. In France, it is still a young discipline. In 2011, a decree entrusted hospital pharmacists with the task of analyzing drug orders [11]; in 2016, clinical pharmacy missions were included in the missions of hospital pharmacies [12]; and finally, in 2019, the clinical pharmacy missions to be carried out were made explicit in the law [13].

The pharmaceutical analysis of orders is the core mission of clinical pharmacists that may lead to a pharmaceutical intervention (i.e., an advice given to the relevant clinician to adapt the treatment or monitor its effects). This activity can only be really performed when the orders are computerized. At Lille academic hospital, the clinical pharmacy roll-out follows that of the computerization of the prescription of medicines. It has been developing since 2015 . Today, approximately 1350 beds are supervised by the 12,8 full-time equivalents pharmacists of the clinical pharmacy department. A clinical pharmacist will oversee one or more clinical units.

\section{Method}

First, in order to have a broad view on clinical pharmacists' activities and to identify the different ways clinical pharmacy is implemented, an exploratory interview was conducted with the right-hand woman of the head of the clinical pharmacy unit. Then, semi-structured interviews were led with clinical pharmacists working within units representing the diversity of the hospital's care offer. Using open-ended questions, the aim was to identify the different work systems, especially tasks performed, work environment, organizations and actors involved in clinical pharmacy activities. The SEIPS (Systems Engineering Initiative for Patient Safety) model was used to structure the data analysis [14]. Interviews were audio-recorded and transcribed. Tasks observations of the clinical pharmacists' activities were performed to enrich the collected data.

\section{Results}

A total of 11 interviews were conducted for an average duration of $70 \mathrm{~min}$. in 11 clinical units where clinical pharmacy missions are implemented. Four observation sessions of the tasks of 3 clinical pharmacists were performed (average duration $=165 \mathrm{~min}$.). 
Five different work systems were identified. Four out of these five work systems were identified as performing pharmaceutical analysis (Table 1). The fifth work system has a clinical pharmacy activity but limited to the management of high-severity alerts delivered by the computerized system. We will focus the description on the other 4 systems and their work organizations supporting the clinical pharmacy activity.

Table 1. Clinical pharmacy activities performed in addition to pharmaceutical analysis along with some elements of the work organization/environment, this according to the unit.

\begin{tabular}{|c|c|c|}
\hline Care units & Clinical pharmacy activities & $\begin{array}{c}\text { Elements of work } \\
\text { organization/environment }\end{array}$ \\
\hline $\begin{array}{l}\text { Surgery } \\
\text { (Including: neurosurgery, } \\
\text { digestive, trauma surgery, } \\
\text { orthopedic and septic } \\
\text { surgery units) }\end{array}$ & $\begin{array}{l}\text { Entry medication reconciliation (except } \\
\text { orthopedic and septic surgery units) } \\
\text { Pre-anesthesia pharmaceutical } \\
\text { consultation (only in neurosurgery unit) } \\
\text { Therapeutical education (only in trauma } \\
\text { surgery unit) }\end{array}$ & $\begin{array}{l}\text { Weekly contribution to clinical } \\
\text { staff }\end{array}$ \\
\hline $\begin{array}{l}\text { Geriatrics } \\
\text { (Including: geriatric } \\
\text { medicine, post-acute and } \\
\text { rehabilitation care units) }\end{array}$ & $\begin{array}{l}\text { Entry and discharge medication } \\
\text { reconciliation } \\
\text { Medication review }\end{array}$ & $\begin{array}{l}\text { Office in the care unit or in the } \\
\text { building }\end{array}$ \\
\hline $\begin{array}{l}\text { Medicine } \\
\text { (Including: neurology, } \\
\text { hematology, gastrology } \\
\text { hospitalization units } \\
\text { gastrology consultations } \\
\text { units) }\end{array}$ & $\begin{array}{l}\text { Entry and discharge medication } \\
\text { reconciliation (discharge only in } \\
\text { neurology unit) } \\
\text { Therapeutical education (only in } \\
\text { neurology and in gastrology } \\
\text { consultations units) }\end{array}$ & $\begin{array}{l}\text { Weekly contribution to medical } \\
\text { rounds }\end{array}$ \\
\hline Penitentiary unit & Therapeutical education & Distant from the hospital building \\
\hline
\end{tabular}

Overall, communication within the four clinical units is mainly carried out via mediated communication (through the electronic health record) when the pharmaceutical intervention is non-urgent or does not need explanation nor to be debated. On the contrary, verbal communication (face-to-face, phone call) is preferred when the intervention is urgent, requires explanation or can lead to a debate on its legitimacy. But there are some specificities according to the work systems.

One of the clinical units is geographically distant from the hospital building, the penitentiary unit. Exchanges between professionals from the unit and clinical pharmacists are mainly limited to those described above.

The other three work systems have organized dedicated synchronous timeslots for clinical units' professionals and clinical pharmacists to discuss synchronously patients' treatments face-to-face. These synchronous communications are organized very differently in the three work systems. But they all allow clinical pharmacists to be directly involved in the therapeutic decision making and to contribute while being aware of the therapeutic objectives for the patient. Awareness of the therapeutic objectives is one of the essential elements to be able to perform the deepest level of prescription analysis, level 3, recommended for patients by the SFPC [15].

Very often, geriatricians are professionals convinced by clinical pharmacy, especially because elderly take many drugs and clinical pharmacy usefulness is quite obvious. It was the first clinical unit to implement medication review in Lille academic hospital: a regular meeting is organized for discharged patients. Moreover, pharmacists in geriatrics are now the only clinical pharmacists to have their office in the care unit or at least in the geriatrics building. Unlike others clinical pharmacists who have their office in the central pharmacy building. Pharmacists in geriatrics are then more willing to gather pharmaceutical interventions to then meet the prescriber face-to-face, while the other 
pharmacists tend to call the prescribers more than they try to meet them as central pharmacy is not at walking distance from the care units.

In medicine units, residents oversee the daily medical rounds. Once a week, a medical round takes place with the head of the department, the doctors and the students. The clinical pharmacist systematically participates in this medical round and therefore can contribute to the therapeutic decisions of the patients.

In surgery units, clinical pharmacists contribute to therapeutic decisions during the weekly clinical staff meeting. But clinical pharmacists express that influencing and changing decisions is not easy. The clinical meeting is structured by the medical point of view, with clinical pharmacy as the "cherry on top". Representations of clinical pharmacy and its contribution are changing but slowly.

\section{Discussion and conclusion}

This exploratory study was conducted to identify the different ways in which clinical pharmacy activities are performed in a large university hospital along with contextual work factors that may influence how they are performed. Results show that a wide variety of clinical pharmacy activities are performed, and that the way they are performed are related to contextual factors of the clinical department. The clinical units concerned are those with computerized therapeutic prescriptions. Some of the units, corresponding to a first work system, remain on a reactive management of the alerts issued by the computer system to adapt the treatments in case of problem. The other four work systems identified engage in anticipatory treatment adaptation activity. Four different work organizations are described for which either the existing organizations have impacted the implementation of clinical pharmacy, or conversely the implementation of clinical pharmacy has impacted the existing activity.

In the penitentiary unit, geographical constraints do not facilitate face-to-face exchanges between the clinical staff and the clinical pharmacist. For units within the hospital, according to the interviews, physicians' perceptions of the benefits of clinical pharmacy have a strong impact on the clinical pharmacy implementation. In surgery, clinical pharmacists participate in the medical staff meeting. However, the meetings are still strongly structured by the doctors, as are the decisions that are finally made. A change in representation is slowly taking place. In medicine and geriatrics, therapeutic decisions are made jointly by physicians and clinical pharmacists, respectively with the pharmacist taking part in medical rounds and dedicated medication review meetings, and in geriatrics even providing the pharmacist with an office on site now.

The main limitation of this study is that, for reasons related to the sanitary context of COVID-19, it was not possible to carry out as many observations as desired in the clinical units. Interviews with clinical pharmacists were therefore preferred. This may represent a bias since this method mainly reflects the perception of clinical pharmacists of their own activity and not their actual activity. Nevertheless, the data collected through interviews with clinical pharmacists converge strongly with those collected during the observations, ensuring a good validity of the data collected. Furthermore, to our knowledge, the main advantage of this study is that it maps the implementation of different clinical pharmacy missions in a large academic hospital.

The next steps in this study are to identify in more detail and in a structured way the factors that influenced the implementation of clinical pharmacy missions in the departments. As clinical pharmacy is a quite new activity in France, its implementation 
and heterogeneity could be explained by the opportunities clinical pharmacists have to disclose to potentially uninformed medical and paramedical teams their abilities within care unit. The perception and the understanding those teams have of the clinical pharmacists' missions will be investigated.

\section{Funding and acknowledgement}

This work was funded by the National Center for Precision Diabetic Medicine PreciDIAB. PreciDIAB is jointly supported by the French Government under the " Investissements d'Avenir » (Investments for the Future) program managed by the " Agence Nationale de la Recherche » (ANR, French National Agency for Research ; reference: ANR-18-IBHU-0001), by the European Union through the « Fonds européen de développement régional » (FEDER - NP0025517) and the "Conseil Régional des Hauts-de-France » (Hauts-de-France Regional Council) (Agreement 20001891/NP0025517), and by the « Métropole Européenne de Lille » (MEL, European Metropolis of Lille) (Agreement 2019_ESR_11). The authors want to thank all clinical pharmacists who agreed to take part in this study.

\section{References}

[1] American College of Clinical Pharmacy. The Definition of Clinical Pharmacy. Pharmacotherapy 2008;28:816-7.

[2] Bond CA, Raehl CL, Franke T. Clinical Pharmacy Services, Pharmacy Staffing, and the Total Cost of Care in United States Hospitals. Pharmacotherapy 2000;20:609-21.

[3] Bond CA, Raehl CL, Franke T. Clinical Pharmacy Services, Hospital Pharmacy Staffing, and Medication Errors in United States Hospitals. Pharmacotherapy 2002;22:134-47.

[4] Bond CA, Raehl CL. Clinical Pharmacy Services, Pharmacy Staffing, and Adverse Drug Reactions in United States Hospitals. Pharmacotherapy 2006;26:735-47.

[5] Bond CA, Raehl CL, Franke T. Interrelationships among Mortality Rates, Drug Costs, Total Cost of Care, and Length of Stay in United States Hospitals: Summary and Recommendations for Clinical Pharmacy Services and Staffing. Pharmacotherapy 2001;21:129-41.

[6] Somers A, Claus B, Vandewoude K, Petrovic M. Experience with the Implementation of Clinical Pharmacy Services and Processes in a University Hospital in Belgium. Drugs Aging 2016;33:189-97.

[7] Penm J, Moles R, Wang H, Li Y, Chaar B. Factors Affecting the Implementation of Clinical Pharmacy Services in China. Qual Health Res 2014;24:345-56.

[8] Brazinha I, Fernandez-Llimos F. Barriers to the implementation of advanced clinical pharmacy services at Portuguese hospitals. Int J Clin Pharm 2014;36:1031-8.

[9] Carter BL. Evolution of Clinical Pharmacy in the USA and Future Directions for Patient Care. Drugs Aging 2016;33:169-77.

[10] Penm J, Chaar B, Moles R. Clinical pharmacy services that influence prescribing in the Western Pacific Region based on the FIP Basel Statements. Int J Clin Pharm 2015;37:485-96.

[11] Arrêté du 6 avril 2011 relatif au management de la qualité de la prise en charge médicamenteuse et aux médicaments dans les établissements de santé. 2011.

[12] Ordonnance $\mathrm{n}^{\circ} 2016-1729$ du 15 décembre 2016 relative aux pharmacies à usage intérieur. 2016.

[13] Décret n²019-489 du 21 mai 2019 relatif aux pharmaciens à usage intérieur. 2019.

[14] Carayon P, Schoofs Hundt A, Karsh B-T, Gurses AP, Alvarado CJ, Smith M, et al. Work system design for patient safety: the SEIPS model. Qual Saf Health Care 2006;15:i50-8.

[15] SFPC. Recommandation de bonne pratique en pharmacie clinique'Niveaux d'analyse pharmaceutique. 2012 [cited sept. 2021]. Available from : http://sfpc.eu/fr/item1/finish/34-documents-sfpc-public/454sfpcrecommandationbppharmaciecliniqueniveauanalysesept $12 / 0 . \mathrm{html}$ 